\title{
ANALISIS DAN PERBANDINGAN AKURASI MODEL PREDIKSI RENTET WAKTU SUPPORT VECTOR MACHINES DENGAN SUPPORT VECTOR MACHINES PARTICLE SWARM OPTIMIZATION UNTUK ARUS LALU LINTAS JANGKA PENDEK
}

\author{
Haldi Budiman ${ }^{1)}$ \\ ${ }^{1)}$ Jurusan Artificial Intelligence, Faculty of Art, Computing, and Creative Industry \\ Universitas Pendidikan Sultan Idris \\ e-mail: naparinhusni@yahoo.co.id ${ }^{1)}$
}

\begin{abstract}
Many algorithms that can be used to predict the traffic flow, there are some who are known algorithms which have a more accurate performance and some are off in the performance test the accuracy of the algorithm. For this algorithm needs to be tested to find out. The proposed method is SVM, SVM-PSO. Compared this method in neural network-based algorithm that has been in curatorial commentary for UJIA rentettime prediction data. Algorithms to be tested is SVM, SVMPSO and Neural Network, which used the data to predict short-term traffic flow. Each of these algorithms will be implemented by using RapidMiner5.1.Performance measurement is doneby calculating the average amount of error that occurs through Root Mean Square Error(RMSE). The smaller the valueof each of the stated performance parameters predicted value closer to the true value. Thus it can be seen that the algorithm is more accurate.
\end{abstract}

Keywords: traffic flow, RMSE, artificial neural networks, support vector machines, svm-pso rentet prediction time

\section{PENDAHULUAN}

Pemerintah khususnya badan perencanaan pembangunan nasional dan daerah harus memiliki konseptualisasi regional untuk pembangunan dan perbaikan sarana dan prasarana transportasi yang dapat membawa pertumbuhan ekonomi .

Pada tahun 2004 sekitar 46,3 persen total panjang jalan mengalami kerusakan ringan dan berat.Pembangunan prasarana transportasi mengalami kendala terutama yang terkait dengan keterbatasan pembiayaan pembangunan, operasi dan pemeliharaan sarana dan prasarana transportasi. Demikian pula kualitas pelayanan angkutan umum yang makin menurun, terjadi tingkat kemacetan dan polusi di beberapa kota besar yang makin parah, serta tingkat kecelakaan yang makin tinggi. Terlebih lagi sejak krisis ekonomi 1998 berdampak pada menurunnya kualitas sarana dan prasarana jalan. Dalam rencana jangka panjang 2005-2025, pembangunan transportasi diarahkan untuk mendukung kegiatan ekonomi, sosial, dan budaya serta lingkungan dan dikembangkan melalui pendekatan pengembangan wilayah agar tercapai keseimbangan dan pemerataan pembangunan antardaerah. Selain itu, perlu ada upaya terus menerus untuk meningkatkan budaya berlalu lintas yang tertib dan disiplin serta mempercepat dan memperlancar pergerakan penumpang dan barang melalui perbaikan manajemen transportasi.

Dasar dan kunci dalam manajemen sistem transportasi cerdas adalah kemampuan untuk prediksi arus lalu lintas jangka pendek secara akurat dan efisien.Prediksi yangtidak akurat menyebabkan perencanaan yang tidak tepat.Pengetahuan mengenai perkiraan kondisi lalu lintas dalam beberapa waktu ke depan akan sangat membantu pihak terkait untuk melakukan sesuatu guna memastikan kelancaran arus lalu lintas.

Data yang tidak liner dan kondisi arus lalu lintas yang tidak homogen, algoritma apakah yang memiliki kinerja lebih akurat dalam memprediksi Arus Lalu Lintas.Sedangkan pertanyaan penelitian (research questions) pada penelitian ini adalah: "Bagaimana akurasi algoritma Support Vector Machines, Support Vector Machines - PSO, untuk memprediksi arus lalulintas jangka pendek?"

Berdasarkan latar belakang dan rumusan masalah diatas, maka penelitian ini bertujuan untuk menentukan algoritma Support Vector Machines, Support Vector Machines - PSOyang 
memiliki kinerja lebih akurat memprediksi arus lalu lintas jangka pendek.

\section{DASAR TEORI}

\subsection{Particle Swarm Optimization}

Particle swarm optimization, disingkat sebagai PSO, didasarkan pada perilaku sebuah kawanan serangga, seperti semut, rayap, lebah atau burung. Algoritma PSO meniru perilaku sosial organisme ini. Perilaku sosial terdiri dari tindakan individu dan pengaruh dari individuindividu lain dalam suatu kelompok. Jadi PSO dikembangkan dengan berdasarkan pada model berikut: Ketika seekor burung mendekati target atau makanan (atau bisa minimum atau maximum suatu fungsi tujuan) secara cepat mengirim informasi kepada burung-burung yang lain dalam kawanan tertentu, Burung yang lain akan mengikuti arah menuju ke makanan tetapi tidak secara langsung, dan Ada komponen yang tergantung pada pikiran setiap burung, yaitu memorinya tentang apa yang sudah dilewati pada waktu sebelumnya.

\subsection{Fungsi Kernel}

Pada umumnya masalah dalam domain dunia nyatajarang yang bersifat linear separable. SVM dimodifikasi dengan memasukan fungsi kernel, untuk menyelesaikan problem non linear.Dalam non linear SVM, data dipetakan oleh fungsi $\Phi$ ke ruang vector yang berdimensi lebih tinggi. Pada ruang vector yang baru kelas Hyperplane yang memisahkan kedua kelas tersebut dapat dikonstruksikan.

Dengan memasukan fungsi kernel pada persaman optimasi SVM, maka persamaan menjadi:

$$
\begin{aligned}
& \max \left\{\sum_{i}^{n} \alpha-\frac{1}{2} \sum_{i, j}^{4} \operatorname{\alpha i\alpha jyiyjK}(\overline{x l}, \bar{x}]\right\} \\
& \sum_{i=1}^{n} \alpha i y i=0 \\
& \mathrm{Bd} \geq 0 \quad \mathrm{i}=1, \ldots, \mathrm{n}
\end{aligned}
$$

\subsection{Komponen Lalu Lintas}

Lalu lintas merupakan suatu interaksi dari berbagai komponen dan perilaku yang membentuk suatu kondisi lalu lintas. Pada dasarnya komponen utama lalu lintas terdiri dari: pemakai jalan, kendaraan dan jalan

\subsection{Volume dan Arus Lalu Lintas}

Lalulintas harian rata-rata (LHR) sering digunakan untuk perencanaan jalan. Volume harian dinyatakan dengan smp per hari. LHR diperoleh dari pengukuran volume lalulintas selama 24 jam pada suatu ruas jalan. Pengukuran ini dilakukan beberapa hari. Hasilnya dirataratakan sehingga menjadi LHR.

Volume Jam Puncak (VJP). Pengukuran volume biasanya dilakukan untuk mengetahui volume jam puncak (VJP). Besaran VJP digunakan untuk perancangan sturktur maupun manajemen lalulintas. Besaran VJP di estimasi dari besaran LHR, sebagaimana persamaan berikut:

$$
V J P=k \cdot L H R
$$

LHR : Lalu lintas selama 24 jam pada hari normal (smp/hari)

VJP : Volume jam puncak pada hari normal (smp/jam)

Nilai k : Proporsi LHR pada jam puncak, sekitar10-11\%

Faktor jam Puncak (FJP). Hubungan antara volume maksimum dan arus maksimum dalam satu jam didefinisikan sebagai faktor jam puncak (FJP). Hubungan tersebut dinyatakan:

$$
F J P=\frac{V}{4 . Q 15}
$$

$\mathrm{V}=$ Volume maksimum dalam waktu satu jam $\mathrm{Q}_{15}=$ Arus lalulintas (smp/15 menit)

\subsection{Support Vector Machines}

Support Vector Machine (SVM) adalah salah satu teknik pembelajaran terawasi yang pertama kali diperkenalkan pada COLT-92 oleh Vapnik, Boser, dan Guyon. SVM dapat digunakan untuk klasifikasi dan juga regresi. SVM juga merupakan metode yang paling banyak digunakan dalam pengenalan pola dan pengenalan objek. Tujuan dari support vector machine adalah untuk membentuk hyperplane sebagai lapisan keputusan sehingga margin yang memisahkan antara contoh positif dan negatif bisa dimaksimalkan dengan pendekatan perubahan optimasi.

Misalkan kita mempunyai fungsi berikut:

$\min f(x)$ dimanaX $(B) \leq X \leq X(A)$

dimana $X$ (B) adalah batas bawah dan $X$ (A) adalah batas atas dari X .

Prosedur PSO dapat dijabarkan dengan langkahlangkah sebagai berikut:

1. Asumsikan bahwa ukuran kelompok atau kawanan (jumlah partikel) adalah $\mathrm{N}$. untuk mengurangi jumlah evaluasi fungsi yang diperlukan untuk menemukan solusi, sebaiknya ukuran $\mathrm{N}$ tidak terlalu besar, tetapi juga tidak terlalu kecil,agar ada banyak 


\section{SYSTEMIC}

Vol. 02, No. 01, Agustus 2016, 19-24

kemungkinan posisi menuju solusi terbaik atau optimal. Jika terlalu kecil, sedikit kemungkinan menemukan posisi partikel yang baik. Terlalu besar juga akan membuat perhitungan jadi panjang.Biasanya digunakan ukuran kawanan adalah 20 sampai 30 partikel.

2. Bangkitkan populasi awal $X$ dengan rentang $X$ (B) dan X (A) secara random sehingga didapat $\mathrm{X} 1, \mathrm{X} 2, \ldots, \mathrm{XN}$. Setelah itu, untuk mudahnya,partikel $\mathrm{j}$ dengan kecepatan pada iretasi I dinotasiakan sebagai $\mathrm{X} \mathrm{j}(\mathrm{i})$ dan $\mathrm{Vj}(\mathrm{i})$ sehingga partikel-partikel awal ini akan menjadi X1(0), X2(0), ..., XN (0). Vektor Xj $(0),(j=1,2, \ldots, N)$ disebut partikel atau vektor koordinat dari partikel. (seperti kromosom dalam algoritma genetika). Evaluasi nilai fungsi tujuan untuk setiap partikel dan nyatakan dengan

$$
f[X 1(0)], f[X 2(0), \ldots, \mathrm{f}[\mathrm{XN}(0)]
$$

3. Hitung kecepatan dari semua partikel. Semua partikel bergerak menuju titik optimal dengan suatu kecepatan. Awalnya semua kecepatan dari partikel diasumsikan sama dengan nol. Set iterasi $\mathrm{i}=1$.

4. Pada iterasi ke-i, temukan 2 parameter penting untuk setiap partikel $\mathrm{j}$ yaitu:

(a) Nilai terbaik sejauh ini dari $\mathrm{Xj}$ (i) (koordinat partikel $\mathrm{j}$ pada iterasi (i) dan nyatakan sebagai Pbest,j, dengan nilai fungsi obyektif paling rendah (kasus minimasi) , f $[\mathrm{Xj}$ (i)], yang ditemui sebuah partikel $\mathrm{j}$ pada semua iterasi sebelumnya.Nilai terbaik untuk semua partikel $\mathrm{Xj}$ (i) yang ditemukan sampai iterasi ke-i, Gbest ,dengan nilai fungsi tujuan paling kecil/minimum diantara semua partikel untuk semua iterasi sebelumnya, f [Xj (i)].

(b) Hitung kecepatan partikel j pada iterasi ke i dengan rumus sebagaiberikut:

$V j(i)=V j(i-1)+$ clel $[$ Pbest,$j-x j(i-1)+$ $c 2 r 2[$ Gbest $-x i(i-1)], j=1,2, \ldots N$

dimana $\mathrm{c} 1$ dan $\mathrm{c} 2$ masing-masing adalah learning rates untuk kemampuan individu (cognitive) dan pengaruh sosial (group), dan r1 dan $\mathrm{r} 2$ bilangan random yang berdistribusi uniforml dalam interval 0 dan 1 . Jadi parameters c1 dan c2 dmenunjukkan bobot dari memory (position) sebuah partikel terhadap memory (posisi) dari kelompok(swarm). Nilai dari c1 dan c2 biasanya adalah 2 sehingga perkalian c1r1 dan c2 r2 memastikan bahwa partikel-partikel akan mendekati target sekitar setengah selisihnya.

(c) Hitung posisi atau koordinat partikel $\mathrm{j}$ pada iterasi ke-i dengan cara

$$
\begin{array}{r}
X j(i)=X j(i-1)+V j(i) ; j \\
=1,2, \ldots, N
\end{array}
$$

Evaluasi nilai fungsi tujuan untuk setiap partikel dan nyatakan sebagai

$$
f[X 19 i), f[X 2(i)], \ldots, f[X N 9 i)]
$$

\subsection{Transform Data}

Data sebelum di masukan ke Rapidminer di transform dengan menggunakan rumus sebagai berikut :

$$
x=0.8 *\left(x^{\prime}-a\right) /(b-a)+(0.1)
$$

Dimana : $\mathrm{a}=$ nilai minimum dan $\mathrm{b}=$ nilai maximum

\subsection{Parameter Evaluasi}

Menurut Carlo Vercellis, adadua alasan utama untuk mengukur akurasi prediksi model time series. Pertama, pada tahap pengembangan dan identifikasi model, ukuran akurasi diperlukan untuk membandingkan model-model alternatif satu sama lain dan untuk menentukan nilai parameter yang muncul dalam ekspresi untuk fungsi prediksi F. Untuk mengidentifikasi model prediksi yang paling akurat, masing-masing model dianggap diterapkan pada data masa lalu, dan model dengan total error minimum dipilih.

Kedua, setelah model prediksi telah dikembangkan dan digunakan untuk menghasilkan prediksi untuk masa mendatang, perlu untuk secara berkala menilai keakuratan, untuk mendeteksi kelainan dan kekurangan dalam model yang mungkin timbul di lain waktu. Evaluasi keakuratan prediksi pada tahap ini membuat mungkin untuk menentukan apakah model masih akurat atau memerlukan suatu revisi.Untuk mengevaluasi akurasi dan peramalan kinerja model berbeda, penelitian ini mengadopsi tiga indeks evaluasi: Percentage Error (MAPE), Mean Square Error (MSE) atau Root Mean Square Error (RMSE) dan Mean Absolute Deviation (MAD). Formula untuk menghitung indeks ini diberikan di bawah ini:

\section{Mean Absolute Percentage Error (MAPE)}

MeanAbsolute Percentage Error adalah nilai absolute dari persentase error data terhadap mean, atau dapat dirumuskan sebagai berikut:

$$
M A P E=\frac{\sum \frac{\mid \text { Prediksi-Aktual } \mid}{\text { Aktual }} \times 100}{n}
$$

Mean Square Error (MSE)

Mean Square Error adalah penjumlahan kuadrat error atau selisih antara nilai sebenarnya (aktual) dan nilai prediksi, kemudian membagi jumlah tersebut dengan banyaknya waktu data peramalan, atau dapat dirumuskan sebagai berikut:

$$
M S E=\frac{\sum(\text { Aktual }- \text { Prediksi })^{2}}{n}
$$

Root Mean Square Error (RMSE)

Root Mean Square Error adalah penjumlahan kuadrat error atau selisih antara nilai sebenarnya 
(aktual) dan nilai prediksi, kemudian membagi jumlah tersebut dengan banyaknya waktu data peramalan dan kemudian menarik akarnya, atau dapat dirumuskan sebagai berikut:

$$
R M S E=\sqrt{\frac{\sum(\text { Aktual-Prediksi })^{2}}{n}}
$$

Mean Absolute Deviation (MAD)

MeanAbsolute Deviation adalah nilai absolutdari penyimpangan data terhadap mean, atau dapat dirumuskan sebagai berikut:

$$
M A D=\frac{\sum \mid \text { Aktual }- \text { Prediksi } \mid}{n}
$$

\subsection{Pembanding Algoritma}

Membandingkan dua atau lebih algoritma dilakukan dengan membandingkan error yang dihasilkan masing-masing algoritma. Untuk mendapatkan perbedaan signifikan secara statistik maka dilakukanlah perbandingan.

Pada beberapa dataset jika ingin melakukan perbandingan dua atau lebih algoritma. Faktor yang membuat perbedaan adalah bahwa suatu algoritma tergantung pada seberapa baik bias induktif yang cocok dengan masalah akan berperilaku berbeda pada dataset yang berbeda, dan nilai kesalahan ini pada set data yang berbeda, tidak bisa dikatakan terdistribusi secara normal sekitar beberapa akurasi rata-rata. Ini berarti perlu untuk menggunakan tes nonparametrik.

Perbandingan ini dapat menggunakan analysis of varian (Anova) satu arah dan Test Kruskal-Wallis. Dengan demikian perbandingan ini dapat menggunakan analysis of varian (Anova) satu arah dan Test Kruskal-Wallis.

\subsection{Analysis of Variance (ANOVA) Satu Arah}

ANOVA satu arah untuk mengetahui apakah data dari beberapa kelompok memiliki rata -rata umum. Maksudnya untuk menetukan apkah ada kelompok yang secara actual berbeda dalam parameter-parameter terukur.

Tabel Error! No text of specified style in document..1 Hasil Keluaran ANOVA Satu

\begin{tabular}{|c|c|c|c|}
\hline $\begin{array}{l}\text { Source of } \\
\text { variation }\end{array}$ & $\begin{array}{c}\text { Sum of } \\
\text { squares }\end{array}$ & $\begin{array}{c}\text { Degrees of } \\
\text { freedom }\end{array}$ & $\begin{array}{c}\text { Mean } \\
\text { square }\end{array}$ \\
\hline $\begin{array}{l}\text { Between } \\
\text { groups }\end{array}$ & $\begin{array}{l}S S_{b} \equiv \\
K \sum_{j}\left(m_{j}-m\right)^{2}\end{array}$ & $L-1$ & $M S_{b}=\frac{S S_{b}}{L-1}$ \\
\hline $\begin{array}{l}\text { Within } \\
\text { groups }\end{array}$ & $\begin{array}{l}S S_{w} \equiv \\
\sum_{j} \sum_{i}\left(X_{i j}-m_{j}\right)^{2}\end{array}$ & $L(K-1)$ & $M S_{w}=\frac{S S_{w}}{L(K-1)}$ \\
\hline Total & $\begin{array}{l}S S_{T} \equiv \\
\sum_{j} \sum_{i}\left(X_{i j}-m\right)^{2}\end{array}$ & $L \cdot K-1$ & \\
\hline
\end{tabular}

Arah

Hasil ANOVA dilaporkan dalam table ANOVA seperti ditunjukan dalam tabel.Tabel menunjukan analisis satu arah dasar di mana factor tunggal, misalnya untuk algoritma Support Vector Machines.

\subsection{Test Kruskal-Wallis}

Test ini adalah versi non-parametrik dari ANOVA satu arah dan merupakan sebuah generalisasi beberapa sampel dari sebuah tes perinkat. Asumsi ini dibalik tes adalah untuk pengukuran berasal dari distribusi yang kontinu, tetapi tidak selalu merupakan distribusi normal. Tes ini berdasarkan analisa varians menggunakan jajran nilai data, bukan nili data iut sendiri perhitungan mirip dengan table ANOVA, dan dapat digambarkan boxplot.

\section{HASIL DAN PEMBAHASAN}

\subsection{Eksperimen dan Pengujian Model}

Algoritma yang diusulkan dalam penelitian ini akan diterapkan pada data arus lalu lintas 2006-2011 ruas Liang Anggang - Martapura.

Support Vector Machines dan Support Vector Machines PSO dalam penelitian ini di terapkan pada data arus lalu lintas 2006-2011 ruas liang Anggang -Martapura dengan Rapidminer. Data di Transform dari data SMP kemudian d masukan ke Rapidminer.

\subsection{Hasil Eksperimen}

Support Vector Machines dan Support Vector Machines - PSO

Hasil penelitian ini menghasilkan Root Mean Squered Error (RMSE) dari algoritma SVM dan SVM_PSO, dibandingakn lagi dengan hasil penelitan Bambang Lareno berbasis Neural Network adalah sebagai berikut :

Tabel 3.1 Nilai RMSE

\begin{tabular}{lll}
\hline Algoritma & $\begin{array}{l}\text { Root } \\
\text { Squered } \\
\text { (RMSE) }\end{array}$ & $\begin{array}{c}\text { Mean } \\
\text { Error }\end{array}$ \\
\hline BPNN & 3,434 & \\
ANFIS & 7,307 & \\
WNN & 2,684 & \\
ENN & 2,722 & \\
SVM & 0,173 & \\
SVM-PSO & 0,160 & \\
SVM(PSO) & 0,179 & \\
\hline
\end{tabular}

HASIL SVM,SVM-PSO, dan SVM(PSO)

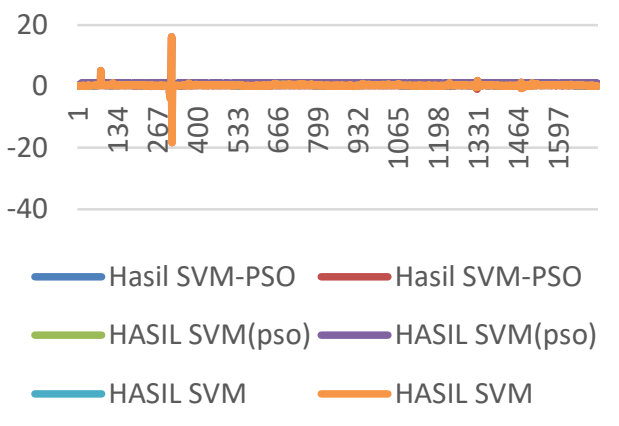




\section{SYSTEMIC}

Vol. 02, No. 01, Agustus 2016, 19-24

Grafik 3.1 Grafik hasil SVM,SVM-PSO dan SVM(PSO

Grafik di atas merupakan hasil gabungan dari algoritma SVM,SVM-PSO,dan SVM(PSO). Hasil yang di peroleh oleh SVM-PSO yang di tempelkan PSO nya ternyata lebih baik.

\section{3 Implikasi Penelitian}

Berdasarkan hasil penelitian dan pengukuran, penerapan algoritma ENN adalah algoritma yang memprediksi arus lalu lintas jangka pendek dengan lebih akurat. Dengan demikian, adanya penerapan algoritma SVM-PSO mampu memberikan solusi bagi petugas mengelola arus lalu lintas maupun instansi terkait, serta menjadi metode prediksi arus lalu lintas jangka pendek dalam rangka manajemen lalu lintas.

\section{Kesimpulan}

Dari hasil penelitan dapat disimpulkan bahwa algoritma Support Vector Machines adalah algoritma Klasifikasi yang bisa digunakan untuk Predisksi rentet waktu. Dari hasil penelitian Support Vector Machines - PSO lebih baik dari Support Vector Machines maupun algoritma berbasis Neural Network. Hal ini di sebabkan data yang tidak linear, arus lalu lintas yang tidak homogen, dan kapasitas jalan yang terbatas. Hasil RMSE untuk Support Vector Machines - PSO adalah 0,160. Hasil RMSE Support Vector Machines(PSO) yang tersedia di RapidMiner ternyata kurang baik akurasinya di bandingakan , Support Vector Machines - PSO yang PSO di tempelkan di Support Vector Machines. Algoritma Support Vector Machines, Support Vector Machines - PSO untuk memprediksi arus lalu lintas, dengan demikian algoritma ini diharapkan mampu memberikan solusi bagi pemerintah untuk mengelola arus lalu lintas, serta menjadi metode prediksi arus lalu lintas jangka pendek dalam manajemen arus lalu lintas.

\section{DAFTAR PUSTAKA}

UNDANG-UNDANG REPUBLIK INDONESIA NOMOR 14 TAHUN 1992 TENTANG LALU LINTAS DAN ANGKUTAN JALAN. 1992.

H. A. Aji, Suraji, Rekayasa Lalu Lintas. 2008, p. 2008.

B. L. H.A, "Analisis dan Perbandingan Akurasi Model Prediksi Rentet Waktu Berbasis Neural Network Untuk Arus Lalu Lintas Jangka Pendek," 2012.

U. Nicholas I. Sapankevych, Raytheon, R. Sankar, and S. Florida, "Using Support Vector Machines: A Survey," no. May, pp. 2438, 2009.

P. V. V. K. Theja, "Short Term Prediction of Traffic Parameters Using Support Vector Machines Technique," pp. 70-75, 2010.

F. Wang, Y. Fang, and G. Tan, "Real-time Traffic Flow Forecasting Based on MWAOSVR," 2009 Third International Symposium on Intelligent Information Technology Application, no. 2, pp. 323326, 2009.

Y. Yang and H. Lu, "Short-trem Traffict Flow Combined Forecasting Model Based on SVM," 2010 International Conference on Computational and Information Sciences, pp. 54-57, Dec. 2010.

R. and and J. K. C. Eberhart, "Particle Swarm Optimization."

B. Birge, “A Particle Swarm Optimization (PSO) Primer."

A. Yunita, C. Fatichah, U. L. Yuhana, J. T. Informatika, U. Islam, M. Malik, I. Malang, J. Teknik, I. Fakultas, and T. Informasi, "IMPLEMENTASI METODE MULTIPLE KERNEL SUPPORT VECTOR MACHINE UNTUK SELEKSI FITUR DARI DATA EKSPRESI GEN DENGAN STUDI KASUS LEUKIMIA DAN TUMOR USUS BESAR."

K. Bangunan, "Survai Pencacahan Lalu Lintas dengan cara Manual,” 2004.

C. \& Hall, The Top Ten Algorithms in Data Mining. .

X. F. Lipo Wang, Data Mining with Computational Intelligence. .

S. Ch, N. Anand, B. K. Panigrahi, and S. Mathur, "Neurocomputing Streamflow forecasting by SVM with quantum behaved particle swarm optimization," Neurocomputing, vol. 101, pp. 18-23, 2013. 
SYSTEMIC

ISSN $\mathbf{2 4 6 0 - 8 0 9 2}$ 